\title{
Impacto do porta-volumes interno para ônibus urbano na qualidade do serviço de transporte público
}

\author{
Igor Augusto Alves Batista ${ }^{1}$, Heloisa Maria Barbosa ${ }^{2}$ e Flávio Henrique Coelho dos Santos ${ }^{3}$
}

\begin{abstract}
Resumo: O artigo apresenta uma avaliação do impacto do porta-volumes interno na qualidade do transporte público. O acessório objetiva proporcionar mais conforto aos usuários e aumentar a capacidade do ônibus. Foi projetado para pessoas portando sacolas, mochilas, pastas, enquanto viajam em pé, e está instalado na parte traseira de um ônibus do sistema de transporte de Belo Horizonte. Os objetivos específicos deste artigo são o estudo de ocupação da linha, determinação da unidade de passageiro padrão e dos níveis de serviço para ônibus urbano para testar se a utilização do porta-volumes em horários de pico pode reduzir o desconforto dos passageiros e diminuir a sensação de superlotação do veículo. O estudo de ocupação determinou a área de projeção de um adulto portando diferentes tipos de bagagem e permitiu criar uma unidade de passageiro padrão que considera a influência da bagagem na área de circulação. Estabeleceu-se o nível de serviço, variando de A (melhor) até $\mathrm{F}$ (pior), conforme a ocupação do ônibus e o conforto do passageiro, considerando o número de assentos ocupados e a densidade de passageiros por metro quadrado. A adoção do porta-volumes gerou impacto positivo na qualidade do serviço, proporcionando mais conforto para os usuários. Assim, recomenda-se sua implantação na totalidade da frota. Caso não seja viável deve-se considerar operar veículos equipados nos horários de maior demanda, ou estudar o uso do portavolumes prioritariamente em rotas que atendam polos, tais como, escolas, supermercados e estações rodoviárias.
\end{abstract} DOI:10.4237/transportes.v21i1.618.

Palavras-chave: porta-volumes interno, ônibus urbano, qualidade do transporte público, nível de serviço.

\begin{abstract}
The paper presents an evaluation of the impact of the internal luggage rack on the public transportation quality. The rack aims at offering more comfort to users and to increase bus capacity. It was designed for passengers carrying bags, backpack, and briefcases while riding standing up, and it is installed on the back part of a bus of Belo Horizonte transport system. Specific objectives of this paper are the bus occupancy study, determination of passenger pattern unity and the level of service for urban buses in order to test whether the use of the rack during peak hours can reduce passenger discomfort and decrease the sensation of vehicle overcrowding. The occupancy study determined the projection area of an adult carrying different types of luggage, and allowed the creation of a passenger pattern unity which takes into account the influence of luggage in the circulation area. Level of service was established varying from A (best) to F (worst), according to bus occupancy and passenger comfort, considering the number of seats taken and passengers density per square meter. The rack adoption generated a positive impact upon service quality, providing more comfort for users. Therefore, its use is recommended to the whole fleet. If not feasible one may consider the operation of equipped vehicles in peak hours, or to study the use of internal luggage rack mainly in bus routes that attend hubs, such as schools, supermarkets and bus stations.
\end{abstract}

Keywords: internal luggage rack, urban bus, public transport quality, level of service.

\section{INTRODUÇÃO}

Atualmente, o sistema de transporte público por ônibus nas cidades grandes e médias brasileiras opera nos horários de maior demanda com superlotação, causando falta de conforto para os usuários, principalmente para aqueles que se encontram em pé. O passageiro portando mochila, sacola, pasta ou bolsa, quando em pé, percebe desconforto não só para ele próprio ao sustentar um peso, mas também para os outros à sua volta, pois o volume carregado dificulta a movimentação de pessoas no corredor do veículo, além de ocupar área destinada aos passageiros.

Para minimizar o problema e proporcionar mais conforto aos usuários foi desenvolvido para testes um porta-volumes

\footnotetext{
${ }^{1}$ Igor Augusto Alves Batista, Departamento de Engenharia Mecânica, Escola de Engenharia da Universidade Federal de Minas Gerais, Belo Horizonte, MG, Brasil. (e-mail: ialvesb@hotmail.com).

${ }^{2}$ Heloisa Maria Barbosa, Núcleo de Transportes, Departamento de Engenharia de Transportes e Geotecnia, Escola de Engenharia da Universidade Federal de Minas Gerais, Belo Horizonte, MG, Brasil. (e-mail: heloisa@etg.ufmg.br).

${ }^{3}$ Flávio Henrique Coelho dos Santos, Núcleo de Transportes, Departamento de Engenharia de Transportes e Geotecnia, Escola de Engenharia da Universidade Federal de Minas Gerais, Belo Horizonte, MG, Brasil. (e-mail: flaviohenriquecoelho@yahoo.com.br).

Manuscrito recebido em 24/8/2012 e aprovado para publicação em $26 / 3 / 2013$. Este artigo é parte de TRANSPORTES v. 21 , n. 1,2013 . ISSN:
} 2237-1346 (online). DOI:10.4237/transportes.v21i1.618. interno para ônibus urbano posicionado sobre os bancos, sem modificar a configuração interna do veículo. $\mathrm{O}$ acessório está instalado na parte traseira de um ônibus urbano do sistema de transporte da cidade de Belo Horizonte, Minas Gerais (ver Figura 1), e poderá ser adotado em outros veículos. O veículo é do tipo Padron com três portas. O projeto, confecção e colocação do acessório bem como a caracterização do perfil do usuário da linha na qual o ônibus equipado com o acessório opera estão descritos em Baptista et al. (2010). O perfil do usuário da referida linha apontou $41,0 \%$ dos passageiros pagantes portando algum tipo de volume, e a grande maioria dos passageiros pagantes em pé, $71,9 \%$, carregando algum pertence. A estratificação por tipo de volume apresentou $48,4 \%$ de mochilas, $20,0 \%$ de pastas, $17,5 \%$ de cadernos/fichários, e $14,1 \%$ de sacolas (Batista et al., 2010). O uso de mochilas é um fato importante para estudar a área ocupada por bagagens, que pode ser revertida para os passageiros com o uso de portavolumes.

O objetivo deste trabalho é apresentar os procedimentos adotados na análise do impacto do porta-volumes na qualidade do serviço de transporte público por ônibus urbano e abordar, principalmente, o aspecto do conforto para o usuário. A metodologia adotada compreendeu o estudo de ocupação da linha, a determinação da unidade de passageiro padrão e dos Níveis de Serviço (NS) para ônibus urbano. O 

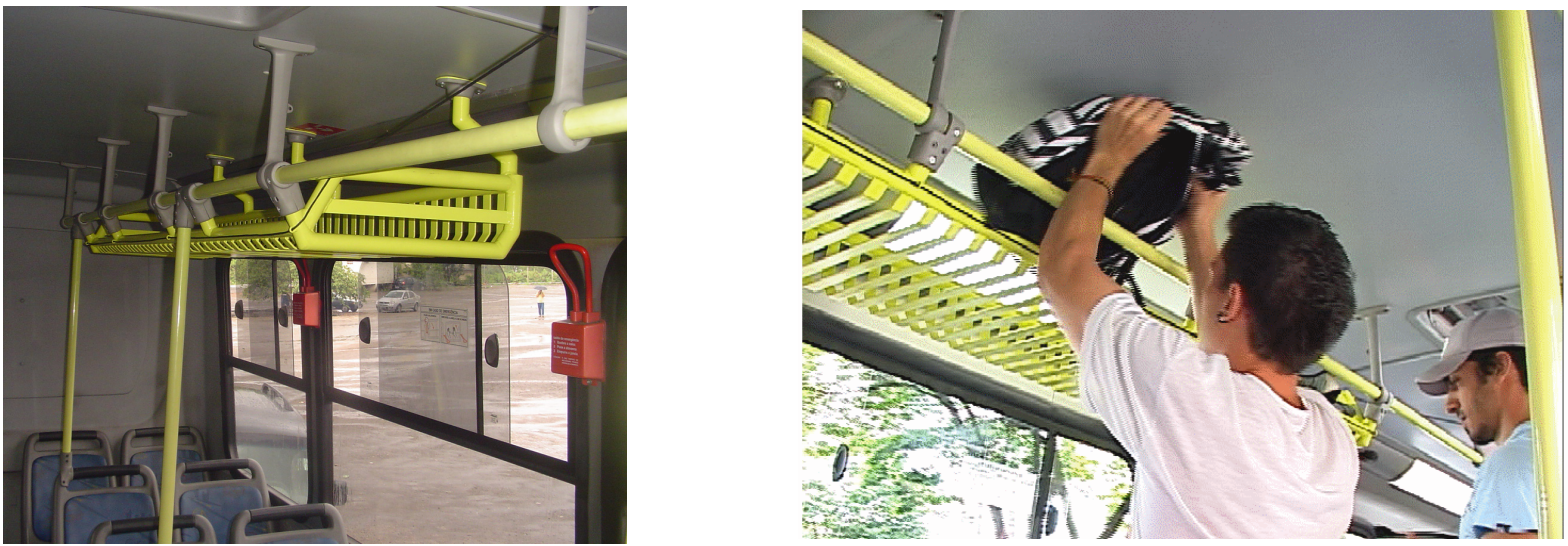

Figura 1. Porta-volumes instalado no ônibus tipo Padron e em uso durante viagem

estudo de caso testou a seguinte hipótese: a utilização do porta-volumes em horários de pico pode reduzir o desconforto dos passageiros e amenizar, ou mesmo diminuir, a sensação de superlotação do veículo, ao retirar volumes e bagagens da área destinada à circulação de passageiros?

\section{QUALIDADE DO SERVIÇO DE TRANSPORTE PÚBLICO}

Nível de serviço é uma medida geral de todas as características de serviço que afetam os usuários do transporte público (Vuchic, 2007). A qualidade do serviço de transporte público é um dos três grupos que compõe o NS, e pode ser definida como os elementos qualitativos, tais como, conveniência e simplicidade de usar o sistema, conforto durante a viagem, estética, limpeza e comportamento dos passageiros (Vuchic, 2007). O nível de serviço para o transporte de passageiros é baseado em duas medidas: fator de carga (passageiros por assento) e área de passageiros em pé, quando alguns passageiros devem ficar em pé ou quando o veículo é projetado para acomodar mais pessoas em pé que sentadas (TRB, 2003). Os limites dos níveis de serviço (de A a F) estabelecidos para a área de passageiros em pé e os respectivos comentários estão na Tabela 1 .

Ferraz e Torres (2004) identificam 12 indicadores de qualidade do transporte público por ônibus: acessibilidade, frequência de atendimento, tempo de viagem, lotação, confiabilidade, segurança, característica da frota e dos locais de parada, sistema de informação, transbordo, comportamento dos operadores, e estado das vias. Para o fator "lotação" adotam como parâmetro de avaliação a taxa de passageiros em pé por metro quadrado que ocupam o espaço livre no interior dos veículos. Os valores da taxa definem o padrão de qualidade em três níveis (bom, regular e ruim).

Conforme Vuchic (2005) a definição de capacidade usada para trens de alta capacidade e serviços de ônibus é expressa em assentos mais a área para viajar em pé, e o conforto do passageiro é computado em função da área livre por passageiro em pé. Em cidades de países desenvolvidos o padrão adotado está entre 4,0 e 5,0 passageiros em pé por metro quadrado. Veículos superlotados são comuns em cidades de países em desenvolvimento e o valor de 6,7 passageiros em pé por metro quadrado é mais usado (ver Tabela 1).

Segundo a EBTU (1988) os seguintes aspectos definem o nível de conforto oferecido: condições de ocupação do veículo, possibilidade de viajar sentado, temperatura interna, condições de ventilação, ruído, aceleração/desaceleração, altura dos degraus, largura das portas e disposição e material dos assentos. A maioria dos aspectos depende do projeto do veículo. No entanto, a ocupação do veículo é o aspecto de conforto mais importante do ponto de vista do usuário. A densidade de ocupação de um veículo de transporte público é definida como a quantidade de passageiros transportados em pé em relação ao espaço útil

Tabela 1. Qualidade do serviço no transporte público - conforto do passageiro

\begin{tabular}{|c|c|c|c|c|c|c|c|}
\hline \multirow[b]{2}{*}{$\begin{array}{l}\text { Qualidade } \\
\text { do serviço }\end{array}$} & \multirow{2}{*}{$\begin{array}{l}\boldsymbol{E B T U}(\mathbf{1 9 8 8 )}) \\
\begin{array}{l}\text { Densidade } \\
\left(\text { pass } / \mathrm{m}^{2}\right)\end{array}\end{array}$} & \multirow{2}{*}{$\begin{array}{l}\text { Ferraze } \\
\text { Torres (2004) } \\
\text { Densidade } \\
\left(\text { pass } / m^{2}\right)\end{array}$} & \multicolumn{3}{|c|}{$T R B(2003)$} & \multicolumn{2}{|c|}{ Vuchic (2005) } \\
\hline & & & $N S$ & $\begin{array}{l}\text { Densidade } \\
\left(\text { pass } / m^{2}\right)\end{array}$ & Comentários & $\begin{array}{l}\text { Densidade } \\
\left(\text { pass } / m^{2}\right)\end{array}$ & $\begin{array}{l}\text { Condição de passageiros em } \\
\text { pé }\end{array}$ \\
\hline Excelente & Só sentados & - & A & $<1,0$ & $\begin{array}{l}\text { Nenhum passageiro } \\
\text { sentado ao lado de } \\
\text { outro }\end{array}$ & $<1,0$ & $\begin{array}{l}\text { Posição independente, fácil } \\
\text { circulação }\end{array}$ \\
\hline Ótimo & 0 a 1,5 & - & B & 1,0 a 1,32 & $\begin{array}{l}\text { Passageiro escolhe } \\
\text { onde sentar }\end{array}$ & \multirow[t]{2}{*}{2 a 3} & \multirow{2}{*}{$\begin{array}{l}\text { Alguns contatos, circulação } \\
\text { incomoda outros }\end{array}$} \\
\hline Bom & 1,5 a 3,0 & $<2,5$ & $\mathrm{C}$ & 1,33 a 1,96 & Todos podem sentar & & \\
\hline Regular & 3,0 a 4,5 & 2,5 a 5,0 & $\mathrm{D}$ & 1,97 a 2,0 & $\begin{array}{l}\text { Lotação em pé } \\
\text { confortável segundo } \\
\text { projeto }\end{array}$ & 4 & $\begin{array}{l}\text { Contatos corporais, } \\
\text { dificuldade de movimentação }\end{array}$ \\
\hline Ruim & 4,5 a 6,0 & $>5,0$ & $\mathrm{E}$ & 2,1 a 5,0 & $\begin{array}{l}\text { Lotação máxima } \\
\text { programada }\end{array}$ & 5 & $\begin{array}{l}\text { Pressionado, extrema } \\
\text { dificuldade de movimentação }\end{array}$ \\
\hline Péssimo & $>6,0$ & - & $\mathrm{F}$ & $>5,0$ & $\begin{array}{l}\text { Passageiros } \\
\text { comprimidos }\end{array}$ & 6,7 & $\begin{array}{l}\text { Comprimido, possíveis } \\
\text { lesões, movimentos forçados }\end{array}$ \\
\hline
\end{tabular}


reservado para a viagem.

A Tabela 1 apresenta uma comparação da qualidade do serviço de transporte público usando o indicador de conforto do passageiro em função da área destinada aos passageiros em pé. Ferraz e Torres (2004) usam três classes para a qualidade. O TRB (2003) adota seis níveis de serviço, idem EBTU (1988), porém com valores distintos quando também comparados com Vuchic (2005), que apresenta cinco classes para a qualidade.

Kawamoto (2010) define o nível de serviço de transporte como um indicador da qualidade do serviço de transporte ofertado, avaliável por meio das reações de usuários e constituído de vários elementos quantificáveis e não quantificáveis. O autor lista 11 variáveis determinantes do nível de serviço em transporte de passageiros, a saber: acessibilidade física, frequência do serviço, confiabilidade do serviço, conforto, tempo de espera, tempo no interior do veículo, transferência, tempo total de viagem, amenidades nos veículos e nos pontos de parada/estações, fluidez no movimento, e segurança. O conceito de conforto é amplo e engloba tudo o que se refere ao bem estar do usuário. Segundo o autor, os determinantes do conforto são: disponibilidade de assento, espaçamento entre assentos, solavancos, aceleração, variação da aceleração, ventilação, temperatura etc. Ainda segundo o autor, a variável síntese do conforto é o nível de lotação, responsável pelo calor, má ventilação e viagem em pé.

Rodrigues e Sorratini (2008), na análise dos resultados da pesquisa com usuários do transporte público de Uberlândia (Minas Gerais) sobre a qualidade do serviço ofertado, notaram que dentre os indicadores sugeridos por Ferraz e Torres (2004), a lotação, confiabilidade, estado das vias, segurança, frequência de atendimento, características dos veículos e características dos locais de parada são os mais importantes para os usuários.

Segundo Iida (1977), a recomendação para dimensionamento da largura do corredor é considerar duas fileiras de pessoas em pé. No entanto, a avaliação das características ergonômicas de dois tipos de ônibus urbano feita por dos Santos (2004) constatou que a largura do corredor, em conformidade com a resolução pertinente, foi considerada pequena por mais de $50 \%$ dos usuários entrevistados, situação agravada quando o ônibus está lotado. Nos horários de pico verificou-se a formação de até três fileiras de usuários no corredor de ambos os veículos.

É tendência recente o uso de porta-volumes em ônibus especiais de ligação centro-aeroporto. O uso de portavolumes em ônibus é tratado especificamente em relação ao Ônibus Rural Escolar - ORE pelo Ministério da Educação (2012). Conforme a sua especificação técnica deve existir um porta-mochilas preso ao teto no sentido longitudinal do ORE, posicionado sobre a fileira de poltronas, com comprimento total igual à extensão desta, medindo $400 \mathrm{~mm}$ de largura e $300 \mathrm{~mm}$ de altura, medidos a partir da janela e do teto, respectivamente, confeccionado em módulos de chapas de aço, dotado de espaços vazados para redução de peso e harmonia visual.

A maioria dos estudos referentes à qualidade do transporte público por ônibus utiliza indicadores agrupados por categorias, considerando todos os aspectos referentes à gerência e operação do sistema. O conforto interno do ônibus pode ser avaliado por diversos aspectos, alguns inerentes ao projeto do veículo. Contudo, a disponibilidade de assento apresenta-se como um dos elementos mais importantes. Em resumo, a lotação do veículo medida pela taxa de passageiros por metro quadrado tem sido considerada como fator determinante do nível de serviço do transporte público.

\section{METODOLOGIA DE TRABALHO}

Esta seção descreve as etapas da metodologia para avaliar o impacto do porta-volumes em ônibus urbano na qualidade do serviço prestado. A primeira etapa consistiu na realização de um estudo de ocupação com o objetivo de determinar a área de projeção de um adulto carregando vários tipos de volume, a saber: mochila, sacola, pasta e cadernos, e na situação sem carregar pertences, bem como de avaliar o impacto dos volumes transportados na capacidade do ônibus e no conforto dos passageiros. O estudo de ocupação foi dividido em dois passos: (i) realização de medições da área de projeção de pessoas, nas situações acima descritas; e (ii) determinação da Unidade de Passageiro Padrão. A segunda etapa da metodologia compreendeu a determinação dos níveis de serviço para o ônibus urbano fundamentado no impacto do transporte de volumes trazidos a bordo pelos passageiros na capacidade do veículo. Após a conclusão dessas etapas foi realizado o estudo de um caso real para a avaliação do porta-volumes a partir do estudo de ocupação e dos níveis de serviço estabelecidos.

\subsection{Estudo de ocupação}

Uma das funções do porta-volumes é aumentar a área interna útil dos veículos disponibilizada para os passageiros pela retirada de volumes/objetos dessa área. É facilmente notado que um passageiro em pé, carregando algum volume, ocupa uma área maior quando comparado a outro passageiro de mãos vazias, sem portar qualquer objeto. Atualmente, para o cálculo da densidade de ocupação no ônibus, número de passageiros em pé por metro quadrado, é considerado apenas a área ocupada por uma pessoa em pé de mãos vazias. A sensação dos passageiros resultante da ocupação do veículo mostra-se superior ao valor calculado, pois se grande parte dos passageiros em pé estiver carregando volumes, o conforto do passageiro será menor e a sensação de superlotação será ainda maior, devido à perda de área destinada aos passageiros para os volumes transportados.

O estudo de ocupação tem por objetivo determinar a área de projeção de um adulto com vários tipos de objetos, a saber: mochila, sacola, pasta e cadernos, e na situação sem volumes, bem como avaliar o impacto dos volumes transportados na capacidade do ônibus e no conforto dos passageiros a fim de estudar a viabilidade da adoção do portavolumes em ônibus urbano. Para as medições da área de projeção de pessoas foi utilizada uma amostra de trinta indivíduos da comunidade universitária. Participaram desse estudo homens e mulheres de diferentes biótipos, estatura, peso e idade. As medições foram realizadas em ambiente controlado (laboratório de transportes) usando hastes de madeira posicionadas verticalmente para delimitar a projeção de cada individuo. A área de projeção foi medida com as mãos vazias, isto é, sem carregar bagagem, com mochila nas costas, com pasta com alça de mão e com sacola/caderno, conforme mostra a Tabela 2. Durante a medição foram usados os volumes pertencentes às pessoas, para considerar as variações de tamanho e conteúdo existentes em um mesmo tipo de volume. 
Tabela 2. Área de projeção de passageiro por tipo de volume

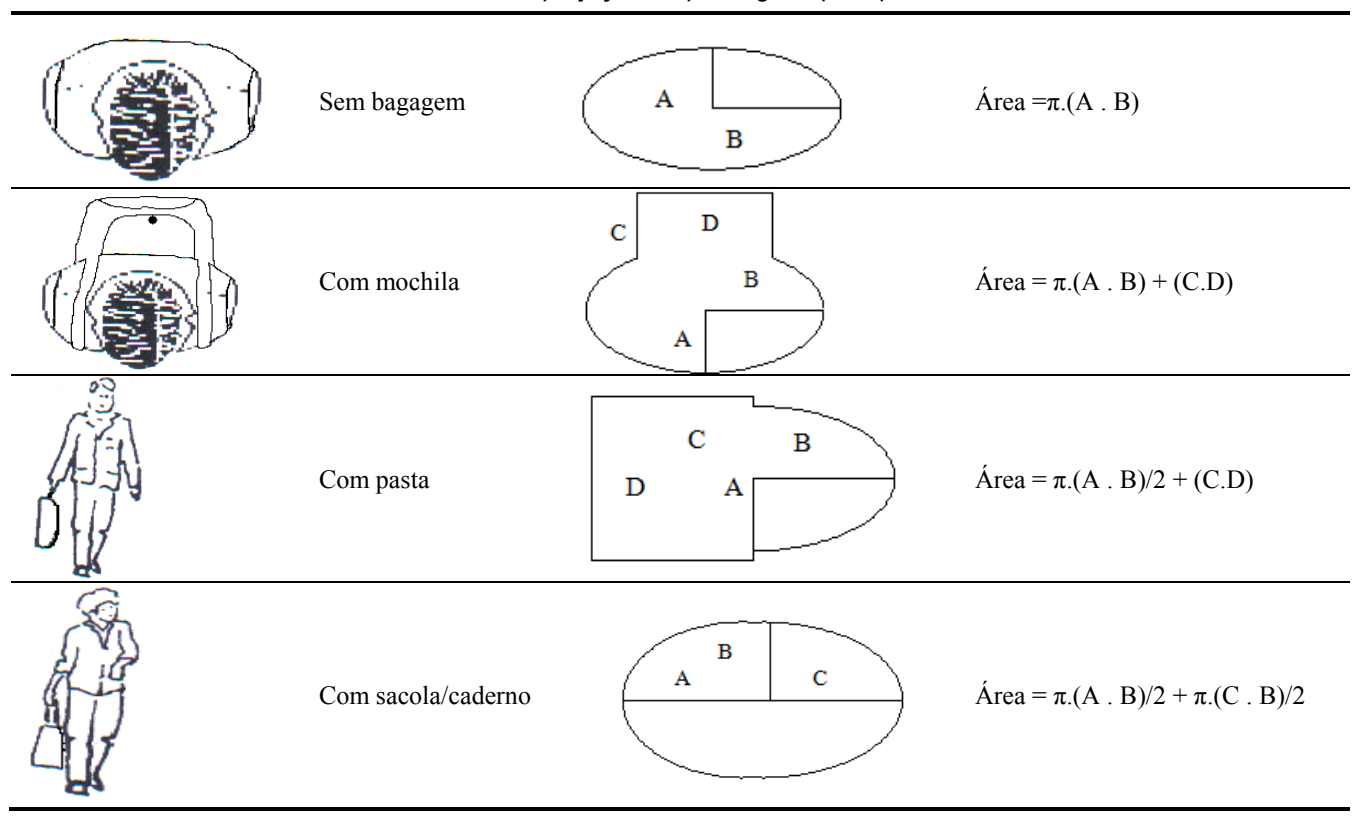

A Unidade de Passageiro Padrão - UPP foi criada como parte da metodologia de estudo da influência de volumes transportados pelos passageiros viajando em pé sobre a capacidade do veículo e o conforto dos usuários do transporte coletivo. Esta unidade é definida como a área média ocupada por um passageiro de mãos vazias, sem portar qualquer tipo de bagagem. Segundo O'Flaherty et al. (1997) a área ocupada por um pedestre (homem) adulto é de $0,14 \mathrm{~m}^{2}$. Todavia, para a determinação da capacidade de calçadas é usado um módulo médio de $0,21 \mathrm{~m}^{2}$ (considerando a elipse corporal de $460 \mathrm{~mm}$ por $610 \mathrm{~mm}$ ). O módulo médio considera o balanço do corpo, o fato de muitos pedestres carregarem artigos pessoais e a preferência psicológica natural de evitar qualquer contato físico com outras pessoas. Segundo a EBTU (1988) estudos desenvolvidos na Europa considerando a elipse corporal do individuo médio e sua proximidade com os demais permitem fixar como condições de conforto:

- 0,16 a 0,20 $\mathrm{m}^{2}$ como mínimo tolerável, para uma pessoa em pé, e em viagens em períodos curtos, com densidade entre 5,0 a 6,0 pessoas $/ \mathrm{m}^{2}$; e

- 0,30 a 0,40 $\mathrm{m}^{2}$ como uma superfície confortável, para transporte de uma pessoa em pé em uma duração um pouco mais longa, com densidade entre 2,5 a 3,5 pessoas $/ \mathrm{m}^{2}$.

Assim, fazendo uma analogia com os estudos de tráfego, a UPP é um fator de equivalência para passageiros com volumes em relação aos passageiros sem volumes. Desta forma, para o cálculo de densidade, a UPP permite transformar "virtualmente" o passageiro com volume em equivalente a uma pessoa sem carregar bagagem. Para efeito deste estudo, considera-se como área a projeção do corpo de um passageiro adulto. Inicialmente foi medida a área de projeção de cada pessoa sem portar volumes, na forma de uma elipse. Para cada tipo de bagagem considerada no estudo em questão foi calculada a área da projeção da pessoa mais o volume portado junto ao corpo. A partir da medição realizada foi calculada a área média ocupada em cada situação e o respectivo fator de equivalência, conforme mostrado na Tabela 3. Todas as medidas efetuadas consideraram a área de projeção exata, sem resguardar distância entre passageiros para evitar contatos físicos indesejados. Ressalta-se que essa condição não proporciona conforto para o passageiro.

Considerou-se como uma unidade de passageiro padrão a área ocupada por um passageiro sem portar qualquer tipo de volume, ou seja, $0,14 \mathrm{~m}^{2}$, obtida a partir das medições realizadas. $\mathrm{O}$ fator de equivalência foi obtido a partir das médias da área de cada pessoa com e sem volume em relação a uma UPP. Um passageiro com um determinado tipo de volume ocupa uma área maior que a de um passageiro padrão. Assim, de acordo com as médias encontradas, mostradas na Tabela 3, tem-se que um passageiro portando uma sacola ou um caderno equivale a $1,1 \mathrm{UPP}$, com uma mochila equivale a 1,4 UPP, e com pasta equivale a 1,6 UPP.

No caso de pessoa carregando pasta foi considerado o balanço do braço que sustenta a pasta, pois a pessoa usa apenas um braço para firmar o corpo e mantê-lo em pé. Assim, a pasta ocupa área maior que a mochila, porém, o desconforto causado por esta é mais percebido pelo usuário, pois por ser carregada nas costas, sua projeção avança sobre o corredor reduzindo a área de circulação, além de estar em contato com o passageiro em pé, no caso de formação de uma segunda fila no corredor. O mesmo não ocorre com a pasta que é portada lateralmente. As bolsas femininas não foram consideradas no estudo, pois por questões de segurança, a pessoa que a carrega não estaria disposta a colocála em um porta-volume, mesmo que estivesse viajando em

Tabela 3. Área média ocupada e fatores de equivalência por tipo de volume

\begin{tabular}{lllll}
\hline & Sem volume & Com sacola/caderno & Com mochila & Com pasta \\
\hline Área média ocupada & $0,14 \mathrm{~m}^{2}$ & $0,16 \mathrm{~m}^{2}$ & $0,19 \mathrm{~m}^{2}$ & $0,23 \mathrm{~m}^{2}$ \\
\hline Fator de equivalência & 1,0 & 1,1 & 1,4 & 1,6 \\
\hline
\end{tabular}


pé, em frente ao porta-volume, de modo a ter ampla visão do mesmo. Os equivalentes de passageiros da Tabela 3 diferem dos valores do TRB (2003): de 0,15 a $0,20 \mathrm{~m}^{2}$ para a área de projeção de um adulto em pé, de 0,25 a $0,30 \mathrm{~m}^{2}$ carregando pastas e de 0,30 a $0,35 \mathrm{~m}^{2}$ com mochilas, que são mais impactantes que as pastas. Ressalta-se que os valores do TRB representa uma condição de maior conforto para os usuários.

A área útil do veículo considerada pela BHTRANS Empresa de Transporte e Trânsito de Belo Horizonte para o cálculo da capacidade (lotação máxima), leva em conta apenas a área de vão livre do corredor, ou seja, não são computadas as áreas de portas e a área destinada ao cadeirante. Porém, a área calculada desta forma não representa a realidade da operação, pois na prática a área de portas e a área do cadeirante, quando esta não se encontra ocupada, também são utilizadas pelos passageiros no caso de veículo lotado. Desta forma, 1,0 $\mathrm{m}^{2}$ de área livre (somente corredor) corresponde a aproximadamente $1,3 \mathrm{~m}^{2}$ de área total, considerando também a área de portas e do cadeirante. Esta proporção refere-se à configuração interna do ônibus equipado com o acessório, utilizado como referência neste trabalho. Para estudar a situação de desconforto vivenciada pelos passageiros, na determinação dos níveis de serviço apresentada na próxima seção, considerou-se a área total real - do veículo, demonstrando, assim, mais fielmente a densidade encontrada dentro do ônibus. A análise da densidade considerando a área livre representa uma situação mais desfavorável para o usuário (maior densidade). A adoção da área total reduz o valor da densidade, porém representa melhor a operação na prática.

\subsection{Determinação do Nível de Serviço}

Os níveis de serviço para ônibus urbano propostos neste trabalho retratam o conforto e a comodidade oferecidos aos passageiros, medidos pelo grau de liberdade na movimentação dentro do ônibus e pela densidade de ocupação do corredor, por meio da taxa de passageiros em pé por metro quadrado. Desta forma foram estabelecidos níveis de servi-

Tabela 4. Características dos Níveis de Serviço propostos para ônibus urbano

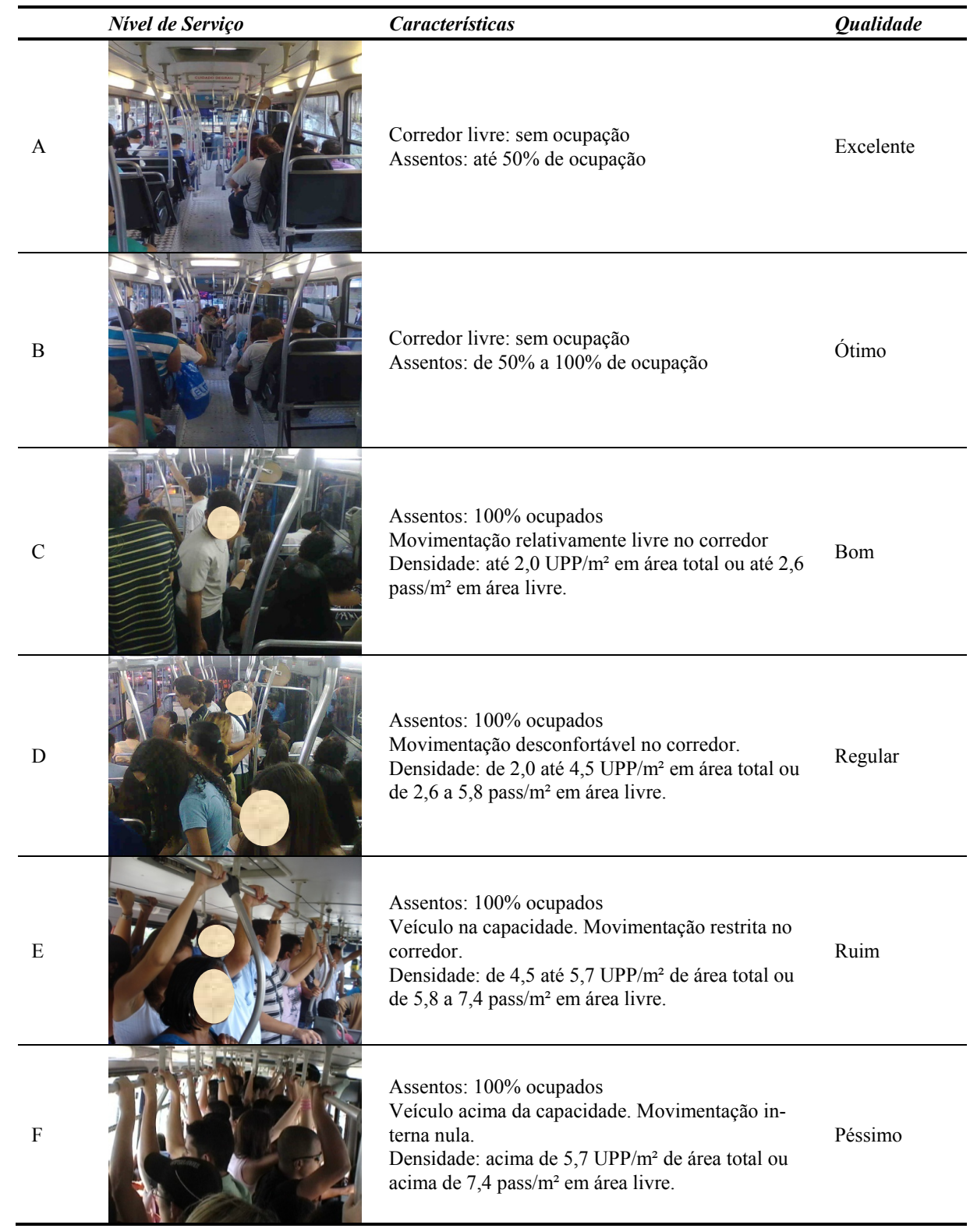


ço de A (melhor) até $\mathrm{F}$ (pior) para a qualidade do espaço disponível para o usuário durante a viagem, descritos abaixo e resumidos na Tabela 4.

Nível - A: O nível de serviço A é definido como o nível de maior conforto: o corredor está completamente livre e os assentos com metade da sua ocupação.

Nivel - B: O nível de serviço B é definido como um nível confortável. O corredor está completamente livre e os assentos com mais da metade da sua ocupação.

Nivel $-C$ : No nível de serviço $\mathrm{C}$ todos os assentos estão ocupados e o corredor apresenta passageiros em pé com baixa densidade de ocupação. A movimentação interna dos passageiros é pouco afetada pela presença dos demais passageiros em pé. A densidade atinge até 2,0 unidades de passageiro padrão em pé por $\mathrm{m}^{2}$ em área total ou até 2,6 passageiros por $\mathrm{m}^{2}$ em área livre. O limite superior para a densidade máxima aceitável deste nível de serviço foi estabelecido em 2,0 unidades de passageiro padrão em pé por $\mathrm{m}^{2}$ em área total. Os passageiros em pé ocupam apenas uma fila no corredor, posicionados lado a lado e ocupam, também, o espaço destinado ao cadeirante.

Nível - D: No nível de serviço D todos os assentos estão ocupados e apresenta passageiros em pé com densidade moderada de ocupação. A movimentação interna dos passageiros é afetada pela presença dos demais passageiros em pé, sendo considerada desconfortável. A densidade varia de 2,0 a 4,5 unidades de passageiro padrão em pé por $\mathrm{m}^{2} \mathrm{em}$ área total ou de 2,6 a 5,8 passageiros em pé por $\mathrm{m}^{2}$ em área livre. O limite superior para a densidade máxima aceitável é 4,5 unidades de passageiro padrão em pé por $\mathrm{m}^{2}$ em área total. Os passageiros em pé posicionam-se lado a lado formando duas filas no corredor, ocupando também parte das áreas de porta e do cadeirante.

Nível - E: O nível de serviço E corresponde a todos os assentos ocupados e passageiros em pé com alta densidade de ocupação (lotado). A movimentação interna dos usuários é muito restrita pela proximidade das pessoas e o desconforto é muito grande. A densidade varia de 4,5 até 5,7 unidades de passageiro padrão em pé por $\mathrm{m}^{2}$ de área total ou de 5,8 a 7,4 passageiros em pé por $\mathrm{m}^{2}$ em área livre. O limite superior para a densidade máxima aceitável deste nível é de 5,7 unidades de passageiro padrão em pé por $\mathrm{m}^{2}$ em área total. Os passageiros em pé formam duas filas no corredor e ocupam toda a área de portas e do cadeirante.

Nível $-F$ : $\mathrm{O}$ nível de serviço $\mathrm{F}$ corresponde à operação do veículo com superlotação. Todos os assentos estão ocupados e a movimentação interna dos passageiros é reduzida a zero pela grande proximidade das pessoas. A densidade atinge valores superiores a 5,7 unidades de passageiro padrão em pé por $\mathrm{m}^{2}$ de área total.

\section{ANÁLISE DO NÍVEL DE SERVIÇO}

Com o objetivo de demonstrar a relação entre a área ocupada por bagagens e a queda no nível de conforto ofertado no transporte coletivo foram utilizados os dados das viagens consideradas na pesquisa de campo na linha em questão. $\mathrm{O}$ estudo de ocupação fundamenta-se nos valores corrigidos pela UPP, a taxa de ocupação da linha no trecho crítico e no percurso crítico, determinados para cada viagem. O trecho crítico corresponde ao espaçamento entre dois pontos de parada de maior carregamento da linha. Em linhas de alta demanda e baixa rotatividade o carregamento se mantém relativamente uniforme com pequenas oscilações devido a poucos embarques/desembarques, durante uma grande extensão do itinerário, representando um período longo de operação em condições semelhantes ao trecho crítico, que nos horários de pico acarretam em um grande desconforto para os usuários. Essa extensão do itinerário foi denominada percurso crítico e corresponde a um valor médio de carregamento para a linha durante a extensão considerada.

Os resultados do estudo da área de projeção (Tabela 3) foram aplicados na avaliação da área útil do ônibus que está ocupada com o transporte de bagagens. Adotou-se a capacidade de cinco passageiros em pé por metro quadrado, considerada confortável conforme o padrão usual do órgão gestor. Ressalta-se que, para Ferraz e Torres (2004) esse valor é aceitável, e considerado um padrão regular de conforto. A análise de ocupação será aqui apresentada para dois períodos típicos, início da manhã e final da noite.

\subsection{Período da manhã}

A viagem iniciou-se às 6:27, sentido Bairro - Centro, no veículo com capacidade de passageiros pagantes em pé em área útil igual a 23 passageiros, e capacidade de passageiros pagantes em pé em área total de 25 passageiros. A variação da capacidade deve-se à presença de um cadeirante na viagem.

A partir das características do veículo e da viagem (Tabela 5) podem-se obter os seguintes dados:

- Densidade em área livre: $5,1 \mathrm{pass} / \mathrm{m}^{2}$;

- Densidade no ponto crítico em área total: 3,8 pass $/ \mathrm{m}^{2}$; e

- Condição operacional correspondente ao Nível de Serviço D.

Considerando a redução de área devido à presença do cadeirante, a densidade é de 4,8 pass $/ \mathrm{m}^{2}$, resultando em condição operacional referente ao Nível de serviço E. A densidade observada em UPP em área total é de 6,0 unidades de passageiro padrão por $\mathrm{m}^{2}$, resultando em uma condição operacional de Nível de serviço F. As bagagens transportadas nessa situação equivalem a 6,1 passageiros a mais no veículo, que corresponde à diferença entre o equivalente de 17 passageiros com bagagens $(23,1)$ e os 17 passageiros sem bagagens.

Para o percurso crítico (Tabela 6) têm-se os seguintes parâmetros operacionais:

- Densidade em área livre: 4,8 passageiros por $\mathrm{m}^{2}$;

- Densidade em área total: 3,6 passageiros por $\mathrm{m}^{2}$; e

- Condição operacional corresponde ao Nível de serviço D.

Considerando a redução de área devido ao cadeirante: 4,7 passageiros por $\mathrm{m}^{2}$, e:

- Condição operacional corresponde ao Nível de ser-

Tabela 5. Trecho crítico - manhã

\begin{tabular}{llllllll}
\hline Pontos & Local & Passageiros em pé & Sem bagagem & Com sacola & Com mochila & Com pasta & Com caderno \\
\hline $9^{\circ}-10^{\circ}$ & Rua Rio Pomba & 23 & 6 & 0 & 8 & 4 & 5 \\
\hline
\end{tabular}


Tabela 6. Percurso crítico: valores médios observados no trajeto

\begin{tabular}{|c|c|c|c|c|c|c|c|}
\hline Trecho: $3^{\circ}$ ao $26^{\circ}$ Ponto & Duração & Passageiros em pé & Sem bagagem & Com sacola & Com mochila & Com pasta & Com caderno \\
\hline Av. Ivaí a Rua Tupinambás & $35 \mathrm{~min}$ & 21 & 5 & 0 & 8 & 5 & 3 \\
\hline
\end{tabular}

viço E;

- Densidade em UPP em área total: 6,3 passageiros padrão por $\mathrm{m}^{2}$; e

- Condição operacional corresponde ao Nível de serviço F.

As bagagens transportadas nessa situação equivalem a 5,1 passageiros a mais no veículo. Devido ao horário de início da manhã, a alta demanda, a baixa rotatividade e a característica de linha radial, resultam em uma grande extensão do percurso crítico. Observa-se neste trecho que devido à presença de bagagens, o nível de serviço piorou de $\mathrm{E}$ para F. Ressalta-se que para o padrão da BHTRANS o veículo não está superlotado, pois apresentou uma densidade inferior a cinco passageiros em pé por $\mathrm{m}^{2}$. Contudo, a sensação dos passageiros é de 5,1 passageiros padrão em pé a mais que o número apresentado, o que se traduz em desconforto para os usuários.

\subsection{Período da noite}

A viagem teve início às 22:15, sentido Área central - Bairro no veículo com capacidade para 23 passageiros pagantes em pé em área livre, e capacidade de 30 passageiros pagantes em pé em área total.

A partir das características do veículo e da viagem (Tabela 7) podem-se obter os seguintes dados, que correspondem à operação no Nível de serviço E:

- Densidade em área livre: 7,3 pass $/ \mathrm{m}^{2}$; e

- Densidade em área total: 5,5 pass $/ \mathrm{m}^{2}$.

Considerando a densidade em UPP para área total obtém-se um valor de 7,5 passageiros padrão por $\mathrm{m}^{2}$, condição operacional corresponde ao Nível de serviço F. As bagagens transportadas nessa situação equivalem a 11,7 passageiros a mais no veículo.

Para o percurso crítico (Tabela 8) têm-se os seguintes parâmetros operacionais:

- Densidade em área livre: 6,9 pass $/ \mathrm{m}^{2}$;

- Densidade em área total: 5,2 pass $/ \mathrm{m}^{2} ; \mathrm{e}$

- Condição operacional corresponde ao Nível de serviço E.

Densidade em UPP em área total: 6,9 passageiros padrão por $\mathrm{m}^{2}$ :

- Condição operacional corresponde ao Nível de serviço F.
As bagagens transportadas nessa situação equivalem a 10,5 passageiros a mais no veículo.

O horário de 22:15 foi o de maior lotação verificado durante a pesquisa. O intervalo mais longo entre veículos, conforme a programação horária, e a coincidência com o horário de saída de estabelecimentos de ensino na região, resultaram na maior densidade verificada. Para a BHTRANS o horário é considerado de alta densidade: 6,9 passageiros em pé. $\mathrm{O}$ horário também apresenta o maior número de passageiros em pé com bagagem, o que eleva muito o número de UPP, consequentemente reduz o conforto do usuário, do nível de serviço $\mathrm{E}$ para o $\mathrm{F}$. A grande quantidade de mochilas faz com que a sensação do usuário seja de mais 10,5 passageiros em pé presentes no veículo. Este horário mostrou-se o de maior necessidade do portavolumes, justificado pelo expressivo número de mochilas a bordo.

\section{DEMANDA X CAPACIDADE DO PORTA- VOLUMES}

Idealmente, o porta-volumes deve ser projetado para atender a demanda dos passageiros no que diz respeito aos volumes portados. Tendo como parâmetro a linha pesquisada foi feita a análise da frota e da área do porta-volumes necessárias para atender a demanda da linha, com o objetivo de melhorar o nível de serviço e aumentar a capacidade de transporte do sistema.

\section{1. Área de projeto do porta-volumes}

Conforme visto anteriormente, as pastas e as mochilas são os maiores volumes carregados por passageiros e, também, os mais frequentes. Desta forma, o dimensionamento do porta-volumes deve ser realizado em função de mochilas e pastas. Cada mochila ocupa uma área correspondente a 0,4 passageiro padrão, e a pasta 0,6 passageiro padrão. Para simplificação, usando como referência o valor médio de 0,5 passageiro padrão, duas pastas ou duas mochilas no portavolume significam um ganho de um passageiro padrão. Dado que $1,0 \mathrm{~m}^{2}$ de porta-volumes apresenta capacidade para seis pastas ou seis mochilas colocadas no acessório e sem sobreposição de bagagens (adotando uma área média igual a $0,17 \mathrm{~m}^{2}$ para pastas e mochilas no acessório), então 1,0 $\mathrm{m}^{2}$ de porta-volumes significaria um ganho de até três passageiros padrão.

Tabela 7. Trecho crítico período noturno

\begin{tabular}{llllllll}
\hline Ponto & Local & $\begin{array}{l}\text { Passageiros } \\
\text { em pé }\end{array}$ & $\begin{array}{l}\text { Sem } \\
\text { bagagem }\end{array}$ & $\begin{array}{l}\text { Com } \\
\text { Sacola }\end{array}$ & $\begin{array}{l}\text { Com } \\
\text { Mochila }\end{array}$ & $\begin{array}{l}\text { Com } \\
\text { Pasta }\end{array}$ & $\begin{array}{l}\text { Com } \\
\text { Caderno }\end{array}$ \\
\hline $12^{\circ}-13^{\circ}$ & Av. Afonso Pena & 33 & 3 & 0 & 19 & 6 & 5 \\
\hline
\end{tabular}

Tabela 8. Percurso crítico: valores médios - final da noite

\begin{tabular}{llllllll}
\hline Trecho: $\mathbf{1 0 ^ { \circ } \text { ao } 1 6 ^ { \circ } \text { Ponto }}$ & Duração & $\begin{array}{l}\text { Passageiros } \\
\text { em pé }\end{array}$ & $\begin{array}{l}\text { Sem } \\
\text { bagagem }\end{array}$ & $\begin{array}{l}\text { Com } \\
\text { Sacola }\end{array}$ & $\begin{array}{l}\text { Com } \\
\text { Mochila }\end{array}$ & $\begin{array}{l}\text { Com } \\
\text { Pasta }\end{array}$ & $\begin{array}{l}\text { Com } \\
\text { Caderno }\end{array}$ \\
\hline $\begin{array}{l}\text { Av. Augusto de Lima - } \\
\text { início R. Pe. Eustáquio }\end{array}$ & $16 \mathrm{~min}$ & 31 & 3 & 0 & 18 & 5 & 5 \\
\hline
\end{tabular}




\subsection{Dimensionamento de frota}

O dimensionamento de frota com porta-volumes deverá ser de acordo com a demanda de cada linha. Para a linha em estudo, a escala de veículos em dia útil prevê a realização de 90 viagens. Dentre essas, as viagens de maior demanda considerando o número de passageiros transportados são mostradas na Tabela 9, em um total de 24 viagens, representando $26,7 \%$ de todas as viagens do dia, para uma frota de 12 veículos. Os veículos assinalados com asterisco fazem mais de uma viagem em horário de pico em um mesmo dia. O cumprimento da programação horária da empresa implica na totalidade da frota, em algum momento, operar em horário de alta demanda, $53,8 \%$ da frota realizar duas ou mais viagens em horário de pico no mesmo dia, e 30,7\% realizar três ou mais viagens no pico.

No caso em questão é recomendável que $100 \%$ da frota seja equipada com o porta-volumes, uma vez que toda a frota opera em horário de pico. Contudo, caso isso não seja possível, a frota indicada para ser equipada com portavolumes, no caso da linha em estudo, corresponde a 53,8\% da frota e no mínimo $30,7 \%$, ou seja, quatro veículos.

\subsection{Eficiência do porta-volumes no veículo teste}

$\mathrm{O}$ veículo equipado com o porta-volumes interno apresenta as seguintes características:

- Área do porta-volumes: $0,83 \mathrm{~m}^{2}$;

- Capacidade do porta-volumes: cinco mochilas ou pastas sem compressão das bagagens;

- Ganho máximo de área: corresponde a 2,5 passageiros padrão; e

- Capacidade: aumento de 33 para até 35,5 passageiros padrão em pé.

No cenário da pesquisa, conforme os dados coletados nos horários de maior demanda, caso o veículo teste fosse utilizado em todas as viagens pesquisadas, o grau de atendimento aos usuários com bagagens teria sido de 16,7\% a $37,3 \%$, como apresentado na Tabela 10. Essa aponta que, apesar da viagem de 22:15 ser a de maior demanda, o atendimento do porta-volumes correspondeu a apenas $16,7 \%$, indicando que a sua capacidade é insuficiente nessa situa- ção.

Desta forma, conclui-se que a área do porta-volumes e, consequentemente, a sua capacidade, devem ser aumentadas. Os cálculos realizados demonstram que o veículo teste ainda não atende toda a demanda nas viagens realizadas em horários de pico da linha e abrange, apenas, em média, 30\% da demanda em uma viagem.

Para aprimoramentos no sistema de transporte público e operação com melhores níveis de serviço recomenda-se que o projeto do porta-volumes interno seja dimensionado de forma a atender toda a demanda de passageiros com bagagem. Idealmente, o porta-volumes interno deve abranger um percentual mais próximo possível da totalidade da frota, se toda a frota operar em horário de pico, uma vez que o porta-volumes se faz mais necessário nesses horários.

Cabe ao órgão gestor e aos empresários estipularem em quais veículos será instalado o acessório. Caso não seja possível a instalação na totalidade da frota, a programação operacional de cada linha deverá considerar a operação dos veículos equipados com porta-volumes nos horários de maior carregamento.

\section{CONSIDERAÇÕES FINAIS}

O porta-volumes interno para ônibus urbano tem por objetivo oferecer mais conforto aos passageiros e aumentar a capacidade do sistema de transporte por ônibus e foi concebido para atender às pessoas que viajam em pé. $\mathrm{O}$ acessório está instalado na parte traseira (após a roleta) de um ônibus urbano do sistema de transporte da cidade de Belo Horizonte. O custo do porta-volumes representa apenas $0,2 \%$ do preço final de um veículo convencional. Esse custo seria ainda menor na possibilidade de produção em escala comercial. A avaliação técnica dos impactos da implantação do porta-volumes foi conduzida por meio de estudo de ocupação da linha, da determinação da unidade de passageiro padrão e dos níveis de serviço para ônibus urbano.

$\mathrm{O}$ estudo de ocupação consistiu em determinar a área de projeção de uma pessoa que porta os tipos de bagagem considerados neste estudo, bem como o impacto desses volumes na capacidade do ônibus e no conforto dos passagei-

Tabela 9. Viagens de maior demanda da linha analisada

\begin{tabular}{llllll}
\hline Horário & Veículo & Horário & Veículo & Horário & Veículo \\
\hline $06: 12$ & $05^{*}$ & $07: 47$ & $01^{*}$ & $16: 40$ & $05^{*}$ \\
\hline $06: 27$ & $06^{*}$ & $10: 46$ & $08^{*}$ & $16: 55$ & $08^{*}$ \\
\hline $06: 35$ & 02 & $12: 38$ & $08^{*}$ & $17: 10$ & $07^{*}$ \\
\hline $06: 42$ & $07^{*}$ & $13: 22$ & $10^{*}$ & $17: 19$ & $09^{*}$ \\
\hline $06: 49$ & $08^{*}$ & $14: 34$ & $05^{*}$ & $17: 29$ & 11 \\
\hline $06: 56$ & $09^{*}$ & $16: 08$ & 03 & $17: 39$ & $10^{*}$ \\
\hline $07: 03$ & $10^{*}$ & $16: 17$ & $01^{*}$ & $17: 49$ & 12 \\
\hline $07: 37$ & 04 & $16: 26$ & $06^{*}$ & $21: 40$ & $09 *$ \\
\hline
\end{tabular}

$\left(^{*}\right)$ veículos com viagens em mais de um horário de pico

Tabela 10. Grau de atendimento aos usuários com bagagens

\begin{tabular}{llll}
\hline Horário & Sentido & $\begin{array}{l}\text { Atendimento máximo de passageiros } \\
\text { com volumes no trecho crítico }\end{array}$ & $\begin{array}{l}\text { Atendimento máximo de passageiros com } \\
\text { volumes no percurso crítico }\end{array}$ \\
\hline $06: 27$ & $\mathrm{~B}-\mathrm{C}$ & $29,4 \%$ & $31,3 \%$ \\
\hline $11: 41$ & $\mathrm{C}-\mathrm{B}$ & $29,4 \%$ & $37,3 \%$ \\
\hline $18: 10$ & $\mathrm{C}-\mathrm{B}$ & $27,0 \%$ & $34,7 \%$ \\
\hline $22: 15$ & $\mathrm{C}-\mathrm{B}$ & $16,7 \%$ & $18,0 \%$ \\
\hline Legenda: B = Bairro e C = Centro
\end{tabular}


ros. A metodologia de trabalho foi dividida em três etapas: (i) realização de medições da área de projeção de pessoas portando bagagens; (ii) determinação da Unidade de Passageiro Padrão - UPP; e (iii) definição dos níveis de serviço para ônibus. A UPP foi definida como a área média ocupada por um passageiro de mãos vazias, sem portar qualquer tipo de bagagem. A partir das medições realizadas com a amostra composta por homens e mulheres, foi calculada a área média ocupada para cada situação e o respectivo fator de equivalência.

Os níveis de serviço para ônibus urbano propostos neste trabalho retratam o conforto e a comodidade oferecidos aos passageiros, medidos pelo grau de liberdade na movimentação dentro do ônibus e pela ocupação do corredor, por meio da densidade de passageiros em pé por metro quadrado. Os valores corrigidos pela UPP para a taxa de ocupação da linha analisada, no ponto crítico e no percurso crítico, determinados para cada viagem por ônibus pesquisada, permitiram mensurar a área útil do ônibus que é ocupada com o transporte de bagagens.

Em algumas viagens a densidade apresentou valores aceitáveis conforme o padrão adotado pela BHTRANS. Porém, a análise pela UPP aponta valores mais elevados, isto é, densidades superiores que indicam um nível de serviço pior. A presença de volumes carregados por passageiros em todas as viagens pesquisadas gera uma sensação de desconforto que pode ser traduzida pelo acréscimo proporcional à presença de aproximadamente cinco passageiros, em média, a mais, com exceção da viagem realizada no final de noite. Nesse último horário, a sensação de desconforto foi muito maior, com um acréscimo correspondente ao dobro do valor verificado nos demais horários, dez passageiros.

Desta forma, o estudo demonstrou o quanto as bagagens oneram o sistema, seja na redução da capacidade veicular ou do conforto do passageiro. O porta-volumes pode ser uma das formas menos onerosas de aumentar o nível de serviço e a capacidade ofertada em períodos de pico. O estudo também permite concluir que o padrão de densidade de cinco passageiros em pé por metro quadrado (densidade utilizada pela BHTRANS), mesmo quando respeitado, implica que a sensação de maior lotação ainda estará presente, devido aos volumes transportados por passageiros.

O porta-volumes com as dimensões atuais tem capacidade para atender aproximadamente $30 \%$ dos volumes transportados em uma viagem. No caso da linha analisada, para um ônibus equipado com porta-volumes atender a demanda de bagagens em uma viagem, a sua área deveria ser superior à área proposta neste estudo. Contudo, a área necessária para suprir toda demanda deve ser projetada de acordo com cada linha. Ressalta-se que há demanda para o uso do porta-volumes nos horários de pico estudados, visto que a maioria dos passageiros em pé portava bagagens passíveis de serem transportadas no acessório.

Para aprimoramentos no sistema de transporte público e operação com melhores níveis de serviço, recomenda-se que a implantação do porta-volumes interno seja ampliada para abranger um percentual mais próximo possível da totalidade da frota. Recomenda-se também uma análise econômica para concluir sobre a melhor estratégia a ser adotada implantar em alguns veículos ou em toda a frota - para evitar que um aumento no custo do veículo tenha reflexo no valor da tarifa. Caso não seja viável o uso do porta-volumes em todos os ônibus, a programação operacional de cada li- nha deverá considerar a operação dos veículos equipados com porta-volumes nos horários de maior demanda. Além disso, para efeito de custo, pode-se estudar a implantação do porta-volumes prioritariamente em linhas que atendam polos, tais como, estabelecimentos de ensino, supermercados e estações rodoviárias.

\section{AGRADECIMENTOS}

Os autores agradecem ao Conselho Nacional de Desenvolvimento e Pesquisa - $\mathrm{CNPq}$ e à Fundação de Amparo à Pesquisa de Minas Gerais FAPEMIG pela concessão de auxílio à pesquisa, e à Viação Euclásio pelo apoio ao projeto.

\section{REFERÊNCIAS}

Batista, I. A. A., H. M. Barbosa, F. H. C. Santos (2010) Bagageiro Interno Aplicado em Ônibus Urbano. Revista dos Transportes Públicos, v. 125 , p. $95-108$.

dos Santos, A. P. (2004) Ergonomia dos Ônibus Urbanos - Estudo de Caso na Cidade de Santos - SP. Dissertação (Mestrado) Universidade Federal de São Carlos, 126 p. Disponível em: <http://www. ergopro.com.br/downloads/Tese\%20Alda.pdf>. (Acesso em 27/ 02/2010).

EBTU - Empresa Brasileira de Transportes Urbanos (1988) Gerência do Sistema de Transporte Público de Passageiros. Elementos Intervenientes. Módulo de Treinamento 2. Brasília, DF.

Ferraz, A.C. P. e I.G.E. Torres (2004) Transporte Público Urbano. Rima, São Carlos. 428 p.

Iida, I. (1977) Aspectos Ergonômicos do Ônibus Urbano, 2. Ministério da Indústria e do Comércio/ Secretaria de Tecnologia Industrial, MIC/STI. Rio de janeiro, RJ.

Kawamoto, E. (2010) Análise de Sistemas de Transporte. Escola de Engenharia de São Carlos, Universidade de São Paulo. $2^{a}$ edição revisada e aumentada, São Carlos. 229 p.

Ministério da Educação (2012) Especificações Técnicas dos Ônibus Rurais Escolares. Termo de Referência ORE 2012. Fundo Nacional de Desenvolvimento da Educação, Brasília.

O’Flaherty C.A., M.G.H. Bell, P.W. Bonsall, A.D. May, C.A. Nash (1997) Transport Planning and Traffic Engineering. Arnold, London. $544 \mathrm{p}$.

Rodrigues, M. A. e J. A. Sorratini (2008) A Qualidade no Transporte Coletivo Urbano. Panorama nacional da pesquisa em transportes 2008: XXII ANPET: Congresso da Associação Nacional de Pesquisa e Ensino em Transportes, Fortaleza, CE. p. 1081-1092.

TRB - Transportation Research Board (2003) Transit Capacity and Quality of Service Manual. Transit Cooperative Research Program. TCRP Report 100. $2^{\text {nd }}$ edition. Washington D.C.

Vuchic V.R. (2005) Urban Transit. Systems and Technology. John Wiley \& Sons, United States. 602 p.

Vuchic V.R. (2007) Urban Transit. Operations, Planning and Economics. John Wiley \& Sons, United States. $644 \mathrm{p}$ 